\title{
Heritability and mechanisms of $n-3$ long chain polyunsaturated fatty acid deposition in the flesh of Atlantic salmon
}

Michael J. Leaver ${ }^{1 *}$, John B. Taggart ${ }^{1}$, Laure Villeneuve ${ }^{1}$, James E. Bron ${ }^{1}$, Derrick R. Guy ${ }^{2}$, Stephen C. Bishop ${ }^{3}$, Ross D. Houston ${ }^{3}$, Oswald Matika ${ }^{3}$, Douglas R. Tocher ${ }^{1}$.

1. Institute of Aquaculture, University of Stirling, Stirling FK9 4LA, UK.

2. Landcatch Natural Selection Ltd, The e-Centre, Cooperage Way, Alloa, Clackmannanshire FK10 3LP, UK.

3. The Roslin Institute and Royal (Dick) School of Veterinary Studies, University of Edinburgh, Roslin Biocentre, Midlothian EH25 9PS, UK.

*Corresponding author. Institute of Aquaculture, University of Stirling, Stirling FK9 4LA, Scotland, UK. Tel: +44 1786 467995; fax; +44 1786472133.

Email address: mjl1@stir.ac.uk

\section{Abstract}

$\mathrm{N}-3$ long chain polyunsaturated fatty acids ( $\mathrm{n}$-3LC-PUFA) are essential components of vertebrate membrane lipids and are crucially deficient in modern Western diets. The main human dietary source for n-3LC-PUFA is fish and seafood, and over $50 \%$ of global fish production is currently supplied by aquaculture. However, increasing pressure to include vegetable oils, which are devoid of $\mathrm{n}$-3LC-PUFA, in aquaculture feeds reduces their content in farmed fish flesh. The aim of this study was to measure the heritability and infer mechanisms determining flesh n-3LC-PUFA content in Atlantic salmon. This was achieved by analysing flesh lipid parameters in 48 families of Atlantic salmon and by measuring differences, by high density microarray, in hepatic mRNA expression in families with high and low flesh n-3LC-PUFA. The results show that flesh n-3LC-PUFA composition is a highly heritable trait $\left(h^{2}=0.77 \pm 0.14\right)$. Gene ontology analysis of differentially expressed genes indicate increased hepatic lipid transport, likely as very low density lipoprotein (VLDL), and implicate increased activity of a transcription factor, hepatic nuclear factor $4 \alpha$ (HNF4 $\alpha$ ), possibly as a result of family differences in transforming growth factor $\beta 1(\operatorname{Tgf} \beta 1)$ signalling. This study paves the way for identification of quantitative trait loci and gene interaction networks that are associated with flesh n-3LC-PUFA composition, which will assist the sustainable production of Atlantic salmon and provide optimal levels of critical nutrients for human consumers. 


\section{Keywords}

n-3LC-PUFA, Atlantic salmon, heritability, liver, flesh, microarray, HNF4 $\alpha$, TGF $\beta 1$

\section{Introduction}

Humans, and probably all other vertebrates require preformed dietary 18:2 n-6 (linoleic acid, LA) and $\alpha-18: 3 n-3$ ( $\alpha$-linolenic acid, ALA) polyunsaturated fatty acids (PUFA) (Burr and Burr, 1930 ; Rivers and Frankel, 1981; Cowey and Cho, 1993). These essential fatty acids cannot be biosynthesised or interconverted in vertebrates, and are primarily derived from plants. LA and ALA have vital functions in themselves, and in turn act as precursors for the long chain PUFA (LC-PUFA) 20:4n-6 (arachidonic acid, ARA), 20:5n-3 (eicosapentenoic acid, EPA) and 22:6n-3 (docosahexanoic acid, DHA). LC-PUFA are essential components of cell membranes, particularly in nervous tissue and their biosynthesis from LA and ALA can be carried out by mammals, although evidence suggests that the process of EPA and particularly DHA biosynthesis from ALA is very low in humans (Burdge and Calder, 2005). The biosynthetic pathway involves consecutive desaturation and elongation reactions that convert LA to ARA and ALA to EPA and DHA. The two main enzyme families involved in these conversions are the elongases of very long fatty acids (Elovl) and the fatty acyl desaturases (Fad) (Cook and McMaster, 2004).

Modern Western diets have an excess of n- 6 PUFA, primarily LA, and because $n-6$ fatty acids and $n-3$ fatty acids cannot be interconverted in vertebrates, this has led to an increase in the tissue ratio of $n-6$ to $n-3$ LC-PUFA. Such imbalances in n- $6 / n-3$ ratios have been linked to several chronic diseases that are particularly prevalent in Western societies including cardiovascular, inflammatory and neurological problems (Calder, 2006). One way of addressing this $n-6 / n-3$ imbalance is to increase the levels of n-3 PUFA and especially n-3LC-PUFA in the diet of humans. Since the conversion of ALA to LC-PUFA has been found to be relatively low in humans, an increase in dietary $n$-3LC-PUFA would be of most benefit. In human diets seafood, particularly oily fish, is the major source of n-3LC-PUFA, and in Western countries minimum consumption levels of fish have been recommended by various health advisory bodies (Scientific Advisory Committee on Nutrition, 2004; Lichtenstein et al., 2006; Scientific Advisory Committee on Nutrition, 2004).

Currently aquaculture produces about $50 \%$ of all fish and seafood for human consumption globally. The formulation of feed is critical for finfish aquaculture, ensuring optimal growth rates and fish welfare, and until recently the bulk feed ingredients have consisted of fish meal and fish oil, extracted from industrial feed-grade capture fisheries. These capture fisheries are now fished at the maximum sustainable limit, and worldwide aquaculture currently consumes the vast majority of the 
resulting fish meal and oil (Tacon and Metian, 2009). Therefore, in order to enable the aquaculture sector to grow in line with consumer demand, alternative bulk feed ingredients are being sought. In recent years, terrestrial plant seed meals and oils, such as those derived from processed soy bean or rapeseed have been used to substitute up to $70 \%$ of fish meal and oil in Atlantic salmon diets with little or no effects on fish growth rate (Torstensen et al., 2005). Like humans, fish require dietary PUFA and LC-PUFA. LC-PUFA are abundant in fish oil, having accumulated ultimately from the phytoplanktonic organisms which form the base of marine food webs (Brett and Muller-Navarra, 1997). However, the flesh of fish fed diets containing plant oils have low levels of the most beneficial n-3LC-PUFA, DHA and EPA, and this deficiency compromises the quality and health benefits of the product (Torstensen et al., 2005).

Unlike some other fish species, Atlantic salmon have the capacity to biosynthesise n-3 and n-6LCPUFA, expressing, predominantly in liver, the $\Delta 5 \mathrm{fad}, \Delta 6 \mathrm{fad}$ and elovl genes necessary. Furthermore, these genes and LC-PUFA biosynthesis are up-regulated after plant oil feeding (Tocher et al., 2001;Zheng et al., 2005a; Leaver et al., 2008; Morais et al., 2009). Nevertheless, the increase in n-3LCPUFA biosynthesis during plant oil feeding is not sufficient to adjust flesh $n$-3LC-PUFA levels to the levels normally expected after fish oil feeding (Leaver et al., 2008). The production of strains of farmed animals with enhanced flesh n-3LC-PUFA would be of great value, and there is evidence from mammals and birds that there is a heritable genetic component governing capacity to biosynthesise and/or deposit LC-PUFA (De Smet et al., 2004;Karamichou et al., 2006;Khang et al., 2007) The aim of this study was to assess whether there is a heritable component in flesh LC-PUFA levels in families of Atlantic salmon fed plant oil, and whether flesh LC-PUFA variability can be explained by gene expression in the liver, the predominant site of LC-PUFA biosynthesis in Atlantic salmon.

\section{Methods}

\subsection{Fish, diet and sampling}

The fish chosen for analysis were from 48 families, randomly selected from a cohort of 200 families that were siblings to the broodstock fish of Landcatch Natural Selection (Alloa, Scotland). These fish were spawned in December 2004, subsequently incubated and hatched in 2005, and maintained as individual families in separate freshwater tanks at Landcatch (Ormsary, Lochgilphead, Scotland). The fish were fed a commercial salmon feed until they had reached an average weight of $71 \pm 9$ in April

2006. Twenty-five smolts from each of the 48 families were transferred to a single seawater tank in April 2006 and, after acclimation, were grown for 12 weeks on an experimental diet with reduced fishmeal, and fish oil replaced with a blend of vegetable oils (50\% rapeseed oil, $30 \%$ palm oil and $20 \%$ camelina oil) as described in detail previously (Petropoulos et al., 2009). The fatty acid composition of the experimental diet is given in Table 1. All fish were tagged with electronic transponders (Pit tags) to allow individual growth to be monitored, with initial fish weights and lengths recorded at tagging. Fish were maintained at ambient temperature and under ambient photoperiod._At harvest, after 12 weeks of feeding the experimental diet, fish weight and length 
were recorded, and a flesh sample (Norwegian Quality Cut) collected, frozen on dry ice and stored at $-20^{\circ} \mathrm{C}$ until analysis. Liver samples were taken from each individual fish and immediately frozen in liquid nitrogen and stored at $-80^{\circ} \mathrm{C}$ prior to RNA extraction.

\subsection{Lipid and fatty acid analysis}

De-boned and skinned flesh samples of equal weight from each fish were combined into 4 pools per family as described previously (Torstensen et al., 2005). Within each family the number of fish per pool was constant, ranging from one to four, with a an overall mean of 2.17 fish per pool. Total lipids were prepared according to the method of Folch et al. (1957) with lipid content determined gravimetrically. Fatty acid methyl esters (FAME) were prepared by acid-catalysed transesterification of total lipids with 19:0 as internal standard according to the method of Christie (2003). Extraction and purification of FAME was performed as described previously (Tocher and Harvie, 1988). FAME were separated and quantified by gas-liquid chromatography using a Thermo Fisher Trace GC 2000 (Thermo Fisher, Hemel Hempstead, UK) equipped with a fused silica capillary column (ZB wax, $30 \mathrm{~m}$ x $0.32 \mathrm{~mm}$ i.d.; Phenomenex, Macclesfield, UK) with hydrogen as carrier gas and using on-column injection. The temperature gradient was from 50 to $150{ }^{\circ} \mathrm{C}$ at $40{ }^{\circ} \mathrm{C} / \mathrm{min}$ and then to $195^{\circ} \mathrm{C}$ at 1.5 ${ }^{\circ} \mathrm{C} / \mathrm{min}$ and finally to $220^{\circ} \mathrm{C}$ at $2{ }^{\circ} \mathrm{C} / \mathrm{min}$. Individual methyl esters were identified by comparison with known standards and by reference to published data (Ackman, 1980). Data were collected and processed using the Chromcard for Windows (version 2.00) computer package (Thermoquest Italia S.p.A., Milan, Italy). Total n-3 LC-PUFA ( $\geq$ C20 and $\geq 3$ double bonds, i.e. mainly 20:4, 20:5, 22:5 and 22:6) content was expressed in relative (percentage of total fatty acids) and absolute (mg fatty acid $/ 100 \mathrm{~g}$ flesh) terms.

\subsection{Heritability Estimates}

Heritabilities for three traits, total flesh lipid level (g/100g flesh), percentage n-3LC-PUFA and total n3LC-PUFA ( $\mathrm{mg} / 100 \mathrm{~g}$ flesh) were estimated by residual maximum likelihood techniques using the ASReml Package (Gilmour et al., 2006). Input data were the mean trait values for each pool of fish for each family. Variance component analyses of these data yields between-family and within-family variance components for each trait. Accounting for the full-sib family structure, and assuming maternal effects are negligible, the between-family variance is an estimate of $\sigma_{g}^{2} / 2$ and the withinfamily variance is an estimate of $\sigma_{g}^{2} / 2 n+\sigma_{e}^{2} / n$, where $\sigma_{g}^{2}$ is the additive genetic variance, $\sigma_{e}^{2}$ is the residual variance and $\mathrm{n}$ is the harmonic mean number of fish per pool, which in this case was 1.8. Rearranging these terms allows the heritability (i.e. $\sigma_{\mathrm{g}}^{2} /\left(\sigma_{\mathrm{g}}^{2}+\sigma_{\mathrm{e}}^{2}\right)$ ) and its standard error to be inferred.

\subsection{Microarrays, Probe Preparation, Hybridization and Data Collection}

Eight families were selected for transcriptomic analysis. The selection criteria ranked families in pairs, each pair with the same total flesh lipid level but with significantly different total n-3LC-PUFA levels, scored as high and low (Table 2). This produced a range of total lipid levels and a range of 
total flesh n-3LC-PUFA levels. Liver was chosen as the target organ because it integrates overall body lipid uptake, dispersion and metabolism and is a major site of $n$-3LC-PUFA biosynthesis, whereas PUFA biosynthesis is virtually undetectable in salmon muscle tissue (Zheng et al., 2005a).

Frozen liver samples (c. $100 \mathrm{mg}$ ) from each individual fish $(n=48)$ were immediately homogenised in 10 volumes of TriReagent (Sigma, Poole, UK). Total RNA was prepared according to the manufacturer's standard protocol. Following spectrophotometric quantitation and quality checking by agarose gel electrophoresis, equal quantities of RNA from each of six individuals were pooled to provide one RNA pool per family. The microarray experiment employed a dual label, pooled reference design, the reference comprising equal amounts of RNA from all samples. Labelled samples (methodology detailed below) were hybridised to the Atlantic salmon TRAITS-SGP 17K cDNA microarray v2 (ArrayExpress accession: A-MEXP-1790; originally described by (Taggart et al., 2008). A dye swap was included in the experimental design. Thus the entire experiment comprised 16 arrays; 8 families $\times 2$ (dye flip).

RNA was reverse transcribed and labelled with either Cy3 or Cy5 using the FAIRPLAY II cDNA labelling kit (Stratagene) according to the manufacturer's instructions. Briefly, $20 \mu \mathrm{g}$ total RNA was reverse transcribed after being primed with oligo dT. Following reverse transcription the RNA template was hydrolysed using $1 \mathrm{M} \mathrm{NaOH}$ for 15 min and then neutralised with $1 \mathrm{M} \mathrm{HCl}$. The cDNA was ethanol precipitated overnight. The cDNA pellets were washed in $80 \%$ ethanol and air-dried before being resuspended in $5 \mu \mathrm{L} 2 \times$ coupling buffer (Stratagene Fairplay Kit). Pre-aliquoted Cy3 and Cy 5 dyes (GE HealthCare; PA23001, PA25001) were resuspended in 45 $\mu$ LMSO prior to being added to coupling buffer. Once the cDNA had fully dissolved (after at least $30 \mathrm{~min}$ ) $5 \mu \mathrm{L}$ Cy dye suspension was added to each tube and these incubated in the dark for $30 \mathrm{~min}$. To remove unincorporated dye, the labelled cDNA (total volume $10 \mu \mathrm{L}$ ) was passed through a DyeEx 2.0 spin column (Qiagen). Dye incorporation was checked by spectrophotometry (NanoDrop ND-1000, NanoDrop Technologies Inc) and by electrophoresis of labelled cDNA on a mini-gel and visualisation by gel scanner (Typhoon Trio, GE Healthcare). For hybridisation, a proportion of each labeled biological replicate and corresponding pooled reference ( $30 \mathrm{pmol}$ each dye, c. $500 \mathrm{ng}$ cDNA) were combined and total volume was made up to $25 \mu \mathrm{L}$ with nuclease-free water. After heating the labelled cDNAs at 95으 for $3 \mathrm{~min}$ in a thermocycler, $225 \mu \mathrm{L}$ of pre-heated $\left(60^{\circ} \mathrm{C}\right)$ hybridisation solution, comprising $185 \mu \mathrm{L} 0.7 \mathrm{X}$ UltraHyb buffer (Ambion), $20 \mu \mathrm{L}$ poly(A) at $10 \mathrm{mg} \mathrm{mL}^{-1}$ (Sigma-Aldrich), $10 \mu \mathrm{L}$ herring sperm at c. 10 $\mathrm{mg} \mathrm{mL}^{-1}$ (Sigma-Aldrich) and $10 \mu \mathrm{L}$ ultra pure BSA at $10 \mathrm{mg} \mathrm{mL}^{-1}$ (Sigma-Aldrich), was added and the mixture was kept at $60^{\circ} \mathrm{C}$ in the dark until being applied to the microarray. Hybridisations (8 slides per day, randomised over two days) were performed in a Lucidea Slidepro semi-automated system (GE Healthcare). Hybridisation mixture $(225 \mu \mathrm{L}$ ) was applied to the microarrays previously loaded into Lucidea Slidepro chambers and maintained at $60^{\circ} \mathrm{C}$. Immediately following this, the chamber temperature was raised to $70^{\circ} \mathrm{C}$ for 10 mins and then lowered to $42^{\circ} \mathrm{C}$, at which temperature hybridisation was continued for 17 hrs with pulse mixing every 15 mins. Following hybridisation, two automatic washes ( $800 \mu \mathrm{L}$ per slide at $8 \mu \mathrm{L} / \mathrm{sec}$ ) were performed with 1.0X SSC; $0.1 \%$ SDS (wash 1 ) and $0.3 \times$ SSC; $0.2 \%$ SDS (wash 2), after which the temperature was lowered to $40 \circ \mathrm{C}$. Slides were then removed from the chambers and further manual washes were performed using the EasyDip ${ }^{\mathrm{TM}}$ 
Slide staining system (Canemco Inc.) on an orbital shaker. Two further washes were performed with wash 2 solution for 3 mins each ( $125 \mathrm{rpm}$; 45 으), followed by $3 \times 2$ min-washes ( $125 \mathrm{rpm} ; 45$ ㅇ) with $0.2 \mathrm{X} \mathrm{SSC}$ and a final $20 \mathrm{sec}$ dip (room temperature) in 0.1X SSC. Slides were then dried by centrifugation ( $500 \mathrm{xg}$ for $5 \mathrm{mins}$ ) and kept in a dessicator and in the dark before being scanned.

Processed microarray slides were scanned at $10 \mu \mathrm{m}$ resolution using a Perkin Elmer

ScanArrayExpress HT scanner. Laser power was kept constant (80\%) and the "auto PMT" function within the acquisition software (v.4) was enabled to adjust PMT for each channel such that less than $0.1 \%$ of features were saturated and that the mean intensity ratio of the Cy3 and Cy5 signals was close to one. BlueFuse software (BlueGnome) was then used to identify and quantify features. Following manual spot editing to remove obvious artifactual features and fusion of duplicate spot data (BlueFuse proprietary algorithm), the resulting intensity values and quality annotations, without positive and negative control features, were exported into the GeneSpring GX version 7.3.1 (Agilent Technologies) analysis platform. Dye-flipped data were subject to transformation, normalisation and quality filtering as follows: 1 ) all raw spot intensity values less than 1 were set to1; 2) a Per Spot and Per Chip Intensity Dependent (Lowess) normalisation was performed using software default values (20\% smoothing, cutoff 10); 3 ) data were filtered using a BlueFuse spot confidence value $\geq 0.1$ in $\geq 4$ slides and BlueFuse quality $>0$ in $\geq 4$ slides. The experimental hybridizations are archived on the EBI ArrayExpress database (http://www.ebi.ac.uk/arrayexpress/) under accession number E-XXXXX (number yet to be assigned). All associated metadata comply with MIAME guidelines.

A list of differentially expressed genes was generated by examining differences between the four families with high percentage $n$-3LC-PUFA at each total lipid level and the four families showing low $n$-3LC-PUFA level at the same total lipid level (T-test, $p<0.05$ ). The putative identity of cDNAs on the microarray was established by comparing cDNA (EST) sequences to the Refseq database of Genbank using BLASTX homology searching. Similarity scores above $\mathrm{e}^{-10}$ were regarded as providing insufficient evidence for encoded protein identity. Array features were further annotated (e.g. for Gene Ontology) as described previously (Taggart et al., 2008). The probability that a particular biological process GO term was enriched in the input GO list (All GO annotations in the TRAITS-GS array) compared to the output GO list (all GO annotations in the experimentally altered gene list) was calculated using a hypergeometric distribution model as implemented by GeneSpring GX 7.3.1.

\subsection{Statistics}

Unless otherwise stated, all data are presented as means \pm SD ( $n$ value as stated). The effects of family on biometry, composition and enzyme activity were analysed by one-way analysis of variance (ANOVA) followed, where appropriate, by Tukey's comparison test. Percentage data and data which were identified as non-homogeneous (Bartlett's test) were subjected to arcsine transformation before analysis. Differences were regarded as significant when $P \leq 0.05$.

\section{Results}




\subsection{Flesh n-3LC-PUFA in families}

Across all families analysed total lipid levels varied between 3.5 and $6.5 \mathrm{~g} / 100 \mathrm{~g}$ flesh and the percentage of $n-3$ LC-PUFA in flesh varied between $9.5 \%$ and $15.6 \%$ of total fatty acids. Comparison of total lipid levels and percentage n-3LC-PUFA showed that these parameters were highly linearly inversely correlated (Table 3 , Fig 1 ) across all of the 48 families. Final mass was also inversely correlated with percentage n-3LC-PUFA. Absolute n-3LC-PUFA levels were highly correlated with lipid levels and lipid levels were correlated to both initial and final mass (Table 3). In contrast there was no evidence of correlation between n-3LC-PUFA level and initial weights, or absolute n-3LCPUFA during the vegetable oil feeding period.

Nevertheless, it was also apparent that some families with the same total flesh lipid level had significantly different percentage $n$-3LC-PUFA levels, which indicated that variation in n-3LC-PUFA composition may not be entirely due to differences in lipid deposition between families.

\section{2. $\underline{\text { Heritabilities }}$}

In total 48 families and 416 fish provided data for the heritability analyses, and the inferred heritabilities are shown in Table 4. These family data indicate that total lipid levels and percentage $n$ 3LC-PUFA are highly heritable, with absolute n-3LC-PUFA levels being moderately heritable. Therefore, in these data a high proportion of the differences seen between individual fish, and between families, are likely to be genetic in origin. Thus, although families show similar total flesh lipid levels, n-LC-PUFA composition is under genetic control.

\subsection{Microarray}

It was not feasible to analyse all 48 families for gene expression using microarrays. Therefore 8 families were selected, and ranked in pairs, with each pair having the same flesh total lipid levels but showing significantly different percentages of n-3LC-PUFA. This allowed a comparison between gene expression profiles associated with high and low $n$-3LC-PUFA, whilst minimising effects of total lipid deposition on gene expression. This comparison resulted in a list of 1345 genes that were differentially expressed between families with high percentage n-3LC-PUFA and those with low percentage n-3LC-PUFA. Application of false discovery correction (FRD, Benjamini and Hochberg, 1995) resulted in a list of only 13 genes. However, since several of the genes in the output list generated before FDR correction were present as more that one feature (eg apolipoprotein B, GAPDH, PTGS etc) it is reasonable to accept the list of 1345 genes as representative of genuine gene expression differences. To increase the robustness of this uncorrected output list, it was further filtered to exclude any gene with less than a 1.25-fold difference between high and low n-3LC-PUFA, resulting in a list of 151 genes, 96 of which had BLASTX hits above the selected cut-off criterion $\left(<\mathrm{e}^{-}\right.$

${ }^{10}$ ) to nr-refseq database entries (Table 5). Over-represented GO terms associated with this filtered list are presented in Table 6. Over-represented biological process categories fell into two main groups: transport, including lipid transport and cell cycle genes. This GO analysis should be treated 
with some caution as it is limited by the incomplete annotation of salmon genes, and is not corrected for false discovery. Nevertheless, investigating in more detail both GO-annotated and GOunannotated gene lists, it is clear that the largest group is involved in lipid transport and lipid metabolism, with plasma liporotein mRNAs (apoB, apoCII, apoA1), cholesterol and phospholipid transport (StarD3 and StarD2), and circulating fatty acid binding proteins (albumin and PTGDS) all having higher hepatic mRNA levels in families with high muscle n-3LC-PUFA. Two important fatty acid metabolism genes, acyl-CoA oxidase and long chain acyl-CoA dehydrogenase were expressed at lower level in families with high percentage n-3LC-PUFA, whilst two glycolytic genes (GAPDH and TPI) were higher in expression. A group of nine genes associated with cell cycle and cell growth were also expressed at lower levels in high n-3LC-PUFA families, whilst extracellular matrix proteins with cell growth functions were increased (LTBP1 and ECM1). LTPB1 was the gene with the highest expression differences between high and low n-3LC-PUFA families, and is responsible for tethering latent TGF $\beta 1$, an important growth regulating cytokine, to the extracellular matrix (Massague, 1998). A group of 14 differentially expressed genes are involved in transcription and transcriptional regulation, some higher and some lower in high n-3LC-PUFA families.

\section{Discussion}

Comparison of 48 randomly selected families of Atlantic salmon indicates that the level of n-3LCPUFA, expressed as a percentage of total fatty acids in muscle, is a highly heritable trait. This and similar traits have also been measured in terrestrial livestock (Karamichou et al., 2006; De Smet et al., 2004) and significant heritabilities also demonstrated. However, the heritability for the percentage flesh n-3LC-PUFA in salmon is considerably higher than for other livestock. It is also apparent that total flesh lipid level also has a high heritable component, and this trait is also well known to be heritable in a variety of farm animal species (Kerry and Ledward, 2009).

Importantly, the absolute level of n-3LC-PUFA in salmon flesh is highly positively correlated with total lipid content because, as the lipid content increases, the content of individual fatty acids, including n-3LC-PUFAs will inevitably increase as well. Both of these parameters were also correlated with growth parameters, intial and final weights. However, the levels of flesh n-3LC-PUFA as a percentage of total fatty acids are inversely correlated with flesh total lipid and with final weight. This is because in the experiment described here the salmon are being fed diets deficient in n-3LCPUFA and the lipid deposited in flesh is reflective of the diet content, thus the more lipid deposited, the lower the percentage n-3LC-PUFA. Nevertheless, there was still a large variation in flesh n-3LCPUFA content between families, even amongst families showing the same total flesh lipid content. Taken together this suggests that families with high flesh n-3LC-PUFA content must either selectively incorporate it into flesh from the small amount still present in the diet, or that the n-3LC-PUFA originates from biosynthesis in either liver or intestine. Liver and intestine are the major sites of synthesis in salmon, muscle biosynthesis being negligible (Tocher et al., 2003). 
Numerous previous studies have demonstrated that n-3 LC-PUFA biosynthesis in both liver and intestine is induced in salmon fed diets deficient in these nutrients (Zheng et al., 2005b;Leaver et al., 2008;Bell et al., 2002;Bell et al., 1997), and this is due to transcriptional activation of genes for the biosynthetic enzymes (Zheng et al., 2004;Leaver et al., 2008;Morais et al., 2009). The driving mechanism for this up-regulation may be the reduced cholesterol content of vegetable oil-based diets, which results in activation of SREBP transcription factors and an increase in mRNA levels of genes involved in cholesterol biosynthesis as well as in LC-PUFA biosynthesis (Leaver et al., 2008; Zheng et al., 2009). The results of the current study indicate that the mRNA levels of hepatic desaturases and elongases, and also of cholesterol biosynthetic enzymes were not different between families, presumably indicating that the vegetable oil diet had similarly increased mRNAs for these proteins in all fish. However there was a clear increase in hepatic mRNA levels for lipid transport genes in families with a high percentage of n-3LCPUFA in flesh, as well as differences in expression of cell cycle and growth related genes, and in genes for secretory pathways and various secreted proteins of the plasma and extracellular matrix.

Although there are limitations to the identification of fish-mammal homologues (or paralogues) based on BLAST, and limitations in the specificity (due to the possibility of cross-hybridisation of related genes) of cDNA arrays such as that used here, it may be possible to infer potential mechanisms for these differences between high and low LC-PUFA families. For example, in mammals several studies have shown that the nuclear receptor HNF4 $\alpha$ (NR2A1) is a major transcriptional regulator of many of the genes listed, particularly the lipid transport lipoproteins, apoB, apoC1 and apoA1, and also of Sepp1 and various members of the Serpin protease inhibitors (Boj et al., 2006;Odom et al., 2004;Kel et al., 2008;Naiki et al., 2002), all of which are among the genes expressed more highly in high LC-PUFA families compared to low. Studies of mice defective for HNF $\alpha$ have shown that this transcription factor is absolutely required for constitutive expression of lipid transport genes responsible for VLDL secretion in liver (Hayhurst et al., 2001). One source of the high $\mathrm{n}$-3LC-PUFA in flesh of some families is presumably liver biosynthesis, because these fatty acids are deficient in the diet. This newly synthesised LC-PUFA must be delivered to tissues as a component of lipoproteins, principally VLDL, synthesised in liver, and it is therefore possible that variations in the activity or expression of hepatic HNF4 $\alpha$ can influence flesh n-3LC- PUFA content.

It is notable that there are significantly differentially expressed genes with homologues whose products are known to form regulatory interactions with HNF $\alpha$ in mammals. The gene with the greatest fold change $(\times 3.55)$ of expression in high compared to low n-3LC-PUFA is LTBP1 (which encodes latent transforming growth factor beta binding protein 1 ). This protein binds Tgf $\beta 1$ (transforming growth factor $\beta 1$ ) and tethers it in latent form to the extracellular matrix, this being a crucial step in regulating Tgf $\beta 1$ function (Ramirez and Rifkin, 2009). Tgf $\beta 1$ is a cytokine with a myriad of functions, including regulation of extracellular matrix synthesis, cell cycle progression and differentiation, as well as being important in cardiovascular, neoplastic and fibrotic disease processes (Massague, 1998). Tgf $\beta 1$ has also been specifically identified as a down-regulator of HNF4 $\alpha$ activity, through activation of SMAD signalling networks (Chou et al., 2003;Cicchini et al., 2006), thus suggesting that LTBP1 might indirectly affect HNF $\alpha$ activity, by virtue of its regulatory 
interaction with $\operatorname{Tgf} \beta 1$. Also relevant is the appearance of Snai1 whose expression is reduced in high LC-PUFA families. Snai1 encodes a gene for a zinc finger transcription factor which also downregulates HNF4 $\alpha$ expression (Cicchini et al., 2006) and is involved in some of the same cellular processes as TGF1 $\beta$. It is also notable, with regard to the actions of TGF $\beta 1$ and Snai1, that the mRNA expression of a group of genes involved in cell cycle progression are decreased in high n-3LC-PUFA salmon families, and a group which encode extracellular matrix components, including LTBP1 are increased.

In addition to the increased expression of lipid transport genes in the livers of salmon families with high flesh n-3LC-PUFA, there are also two genes that are instrumental in fatty acid metabolism and which are decreased in these families. These genes encode acyl-CoA oxidase (ACOX1) and a long chain acyl CoA dehydrogenase (ACADL). Since these enzymes can metabolise n-3LC-PUFA, a reduction in levels might lead to an increase in supply in the liver, and thus also increase availability for export to other tissues.

A variety of genes whose products are involved in transcription, protein processing and transport, or are involved in the regulation of these pathways, are differentially expressed when comparing high and low n-3LC-PUFA families. Since it is appears that a number of lipid transport, metabolic and cell cycle process genes differ in expression, it could be surmised that any resulting differences in these transcriptional and protein processing pathways were associated with the specific requirements of lipid transport, metabolism and growth.

In conclusion this study has established that n-3LC-PUFA level is a highly heritable trait in Atlantic salmon, and that there are specific hepatic mRNA expression patterns associated with high flesh $n$ 3LC-PUFA, which indicate possible mechanisms for family-dependent deposition in flesh. Thus, this study opens the way to identifying quantitative trait loci for n-3LC-PUFA level in Atlantic salmon fed LC-PUFA deficient diets, an important objective given the current constraints on the supply of these valuable fatty acids, and their critical role in human nutrition.

\section{Acknowledgements}

This study was supported by contract number 016249-2 of the project 'Sustainable Aquafeeds to Maximise the Health Benefits of Farmed Fish for Consumers' (Aquamax) as part of the EU FP6 programme Food Quality and Safety. L. Villeneuve was supported by a European Union Marie Curie Fellowship (MAST, project number: EIF-024589). The authors would also like to thank the staff of Landcatch Ltd. for fish husbandry and help with sampling, and Technology Crops Ltd. for supplying Camelina oil.

\section{References}


Ackman,RG., 1980. Fish Lipids. In: Connell JJ. (Ed.), Advances in Fish Science and Technology, Fishing News Books, Farnham, pp. 83-103.

Bell,J.G., Henderson,R.J., Tocher,D.R., Mcghee,F., Dick,J.R., Porter,A., Smullen,R.P. and Sargent,J.R., 2002. Substituting fish oil with crude palm oil in the diet of atlantic salmon (Salmo salar) affects muscle fatty acid composition and hepatic fatty acid metabolism. Journal of Nutrition. 132, 222-230.

Bell,J.G., Tocher,D.R., Farndale,B.M., Cox,D.I., Mckinney,R.W. and Sargent,J.R., 1997. The effect of dietary lipid on polyunsaturated fatty acid metabolism in atlantic salmon (Salmo salar) undergoing parr-smolt transformation. Lipids. 32, 515-525.

Benjamini,Y. and Hochberg,Y., 1995. Controlling the False Discovery Rate - A Practical and Powerful Approach to Multiple Testing. Journal of the Royal Statistical Society Series BMethodological. 57, 289-300.

Boj,S.F., Servitja,J.M., Pozo,N., Papatheodorou,I. and Ferrer,J., 2006. Global analysis of gene expression profiles reveals both shared and distinct roles of HNF4 alpha. Diabetologia. 49, 86.

Brett,M.T. and Muller-Navarra,D.C., 1997. The role of highly unsaturated fatty acids in aquatic food web processes. Freshwater Biology. 38, 483-499.

Burdge,G.C. and Calder,P.C., 2005. Conversion of alpha-linolenic acid to longer-chain polyunsaturated fatty acids in human adults. Reproduction Nutrition Development. 45, 581597.

Burr,G.O. and Burr,M.M., 1930. On the nature and role of the fatty acids essential in nutrition. Journal of Biological Chemistry. 86, 0587-0621.

Calder,P.C., 2006. n-3 polyunsaturated fatty acids, inflammation, and inflammatory diseases. American Journal of Clinical Nutrition. 83, 1505S-1519S.

Chou,W.C., Prokova,V., Shiraishi,K., Valcourt,U., Moustakas,A., Hadzopoulou-Cladaras,M., Zannis,V.I. and Kardassis,D., 2003. Mechanism of a transcriptional cross talk between transforming growth factor-beta-regulated Smad3 and Smad4 proteins and orphan nuclear receptor hepatocyte nuclear factor-4. Molecular Biology of the Cell. 14, 1279-1294.

Christie,WW., 2003. Lipid Analysis, 3rd Edition edn. The Oily Press, Bridgewater, UK. 
Cicchini,C., Filippini,D., Coen,S., Marchetti,A., Cavallari,C., Laudadio,I., Spagnoli,F.M., Alonzi,T. and Tripodi,M., 2006. Snail controls differentiation of hepatocytes by repressing HNF4 alpha expression. Journal of Cellular Physiology. 209, 230-238.

Cook,H.W. and McMaster R.C.R., 2004. Fatty acid desaturation and chain elongation in eukaryotes. In: Vance D.E. and Vance J.E. (Eds.), Biochemistry of Lipids, Lipoproteins and Membranes, Elsevier, Amsterdam.

Cowey,C.B. and Cho,C.Y., 1993. Nutritional-requirements of fish. Proceedings of the Nutrition Society. 52, 417-426.

De Smet,S., Raes,K. and Demeyer,D., 2004. Meat fatty acid composition as affected by fatness and genetic factors: a review. Animal Research. 53, 81-98.

Folch,J., Lees,M. and Stanley,G.H.S., 1957. A Simple Method for the Isolation and Purification of Total Lipides from Animal Tissues. Journal of Biological Chemistry. 226, 497-509.

Gilmour,A., Gogel,B., Cullis,B. and Thompson,R., 2006. ASReml User Guide Release 2.0. VSN International Ltd, Hemel Hempstead, UK.

Hayhurst,G.P., Lee,Y.H., Lambert,G., Ward,J.M. and Gonzalez,F.J., 2001. Hepatocyte nuclear factor 4 alpha (nuclear receptor 2a1) is essential for maintenance of hepatic gene expression and lipid homeostasis. Molecular and Cellular Biology. 21, 1393-1403.

Karamichou,E., Richardson,R.I., Nute,G.R., Gibson,K.P. and Bishop,S.C., 2006. Genetic analyses and quantitative trait loci detection, using a partial genome scan, for intramuscular fatty acid composition in Scottish Blackface sheep. Journal of Animal Science. 84, 3228-3238.

Kel,A.E., Niehof,M., Matys,V., Zemlin,R. and Borlak,J., 2008. Genome wide prediction of HNF4 alpha functional binding sites by the use of local and global sequence context. Genome Biology. 9.

Kerry,J. and Ledward,D., 2009. Improving the sensory and nutritional quality of fresh meat Woodhead Publishing Ltd., Great Abington, Cambridge.

Khang,N.T.K., Jennen,D.G.J., Tholen,E., Tesfaye,D., Mennicken,L., Hoelker,M., Schellander,K., Ponsuksili,S., Murani,E. and Wimmers,K., 2007. Association of the FADS2 gene with omega-6 and omega-3 PUFA concentration in the egg yolk of Japanese quail. Animal Biotechnology. $18,189-201$. 
Leaver,M.J., Villeneuve,L.A.N., Obach,A., Jensen,L., Bron,J.E., Tocher,D.R. and Taggart,J.B., 2008. Functional genomics reveals increases in cholesterol biosynthetic genes and highly unsaturated fatty acid biosynthesis after dietary substitution of fish oil with vegetable oils in Atlantic salmon (Salmo salar). Bmc Genomics. 9.

Lichtenstein,A.H., Appel,L.J., Brands,M., Carnethon,M., Daniels,S., Franch,H.A., Franklin,B., KrisEtherton,P., Harris,W.S., Howard,B., Karanja,N., Lefevre,M., Rudel,L., Sacks,F., Van Horn,L., Winston,M. and Wylie-Rosett,J., 2006. Diet and lifestyle recommendations revision 2006 - A scientific statement from the American Heart Association Nutrition Committee. Circulation. 114, 82-96.

Massague,J., 1998. TGF-beta signal transduction. Annual Review of Biochemistry. 67, 753-791.

Morais,S., Monroig,O., Zheng,X.Z., Leaver,M.J. and Tocher,D.R., 2009. Highly Unsaturated Fatty Acid Synthesis in Atlantic Salmon: Characterization of ELOVL5-and ELOVL2-like Elongases. Marine Biotechnology. 11, 627-639.

Naiki,T., Nagaki,M., Shidoji,Y., Kojima,H., Imose,M., Kato,T., Ohishi,N., Yagi,K. and Moriwaki,H., 2002. Analysis of gene expression profile induced by hepatocyte nuclear factor 4 alpha in hepatoma cells using an oligonucleotide microarray. Journal of Biological Chemistry. 277, 14011-14019.

Odom,D.T., Zizlsperger,N., Gordon,D.B., Bell,G.W., Rinaldi,N.J., Murray,H.L., Volkert,T.L., Schreiber,J., Rolfe,P.A., Gifford,D.K., Fraenkel,E., Bell,G.I. and Young,R.A., 2004. Control of pancreas and liver gene expression by HNF transcription factors. Science. 303, 1378-1381.

Petropoulos,I.K., Thompson,K.D., Morgan,A., Dick,J.R., Tocher,D.R. and Bell,J.G., 2009. Effects of substitution of dietary fish oil with a blend of vegetable oils on liver and peripheral blood leucocyte fatty acid composition, plasma prostaglandin E-2 and immune parameters in three strains of Atlantic salmon (Salmo salar). Aquaculture Nutrition. 15, 596-607.

Ramirez,F. and Rifkin,D.B., 2009. Extracellular microfibrils: contextual platforms for TGF beta and BMP signaling. Current Opinion in Cell Biology. 21, 616-622.

Rivers,J.P.W. and Frankel,T.L., 1981. Essential Fatty-Acid Deficiency. British Medical Bulletin. 37, 5964.

Scientific Advisory Committee on Nutrition. Advice on fish consumption: benefits and risks. http://www.food.gov.uk/news/newsarchive/2004/jun/fishreport2004, Food Standards Agency, UK . 2004. 
Tacon,A.G.J. and Metian,M., 2009. Fishing for Aquaculture: Non-Food Use of Small Pelagic Forage Fish-A Global Perspective. Reviews in Fisheries Science. 17, 305-317.

Taggart,J.B., Bron,J.E., Martin,S.A.M., Seear,P.J., Hoyheim,B., Talbot,R., Carmichael,S.N., Villeneuve,L.A.N., Sweeney,G.E., Houlihan,D.F., Secombes,C.J., Tocher,D.R. and Teale,A.J., 2008. A description of the origins, design and performance of the TRAITS-SGP Atlantic salmon Salmo salar L. cDNA microarray. Journal of Fish Biology. 72, 2071-2094.

Tocher,D.R., Bell,J.G., Macglaughlin,P., Mcghee,F. and Dick,J.R., 2001. Hepatocyte fatty acid desaturation and polyunsaturated fatty acid composition of liver in salmonids: effects of dietary vegetable oil. Comparative Biochemistry and Physiology B-Biochemistry \& Molecular Biology. 130, 257-270.

Tocher,D.R., Bell,J.G., Mcghee,F., Dick,J.R. and Fonseca-Madrigal,J., 2003. Effects of dietary lipid level and vegetable oil on fatty acid metabolism in Atlantic salmon (Salmo salar L.) over the whole production cycle. Fish Physiology and Biochemistry. 29, 193-209.

Tocher,D.R. and Harvie,D.G., 1988. Fatty-Acid Compositions of the Major Phosphoglycerides from Fish Neural Tissues - (N-3) and (N-6) Poly-Unsaturated Fatty-Acids in Rainbow-Trout (Salmo gairdneri) and Cod (Gadus morhua) Brains and Retinas. Fish Physiology and Biochemistry. 5, 229-239.

Torstensen,B.E., Bell,J.G., Rosenlund,G., Henderson,R.J., Graff,I.E., Tocher,D.R., Lie,O. and Sargent,J.R., 2005. Tailoring of Atlantic salmon (Salmo salar L.) flesh lipid composition and sensory quality by replacing fish oil with a vegetable oil blend. Journal of Agricultural and Food Chemistry. 53, 10166-10178.

Zheng,X.Z., Leaver,M.J. and Tocher,D.R., 2009. Long-chain polyunsaturated fatty acid synthesis in fish: Comparative analysis of Atlantic salmon (Salmo salar L.) and Atlantic cod (Gadus morhua L.) Delta 6 fatty acyl desaturase gene promoters. Comparative Biochemistry and Physiology B-Biochemistry \& Molecular Biology. 154, 255-263.

Zheng,X.Z., Tocher,D.R., Dickson,C.A., Bell,J.G. and Teale,A.J., 2004. Effects of diets containing vegetable oil on expression of genes involved in highly unsaturated fatty acid biosynthesis in liver of Atlantic salmon (Salmo salar). Aquaculture. 236, 467-483.

Zheng,X.Z., Tocher,D.R., Dickson,C.A., Bell,J.G. and Teale,A.J., 2005a. Highly unsaturated fatty acid synthesis in vertebrates: New insights with the cloning and characterization of a Delta 6 desaturase of Atlantic salmon. Lipids. 40, 13-24. 
Zheng,X.Z., Torstensen,B.E., Tocher,D.R., Dick,J.R., Henderson,R.J. and Bell,J.G., 2005b.

Environmental and dietary influences on highly unsaturated fatty acid biosynthesis and expression of fatty acyl desaturase and elongase genes in liver of Atlantic salmon (Salmo salar). Biochimica Et Biophysica Acta-Molecular and Cell Biology of Lipids. 1734, 13-24. 


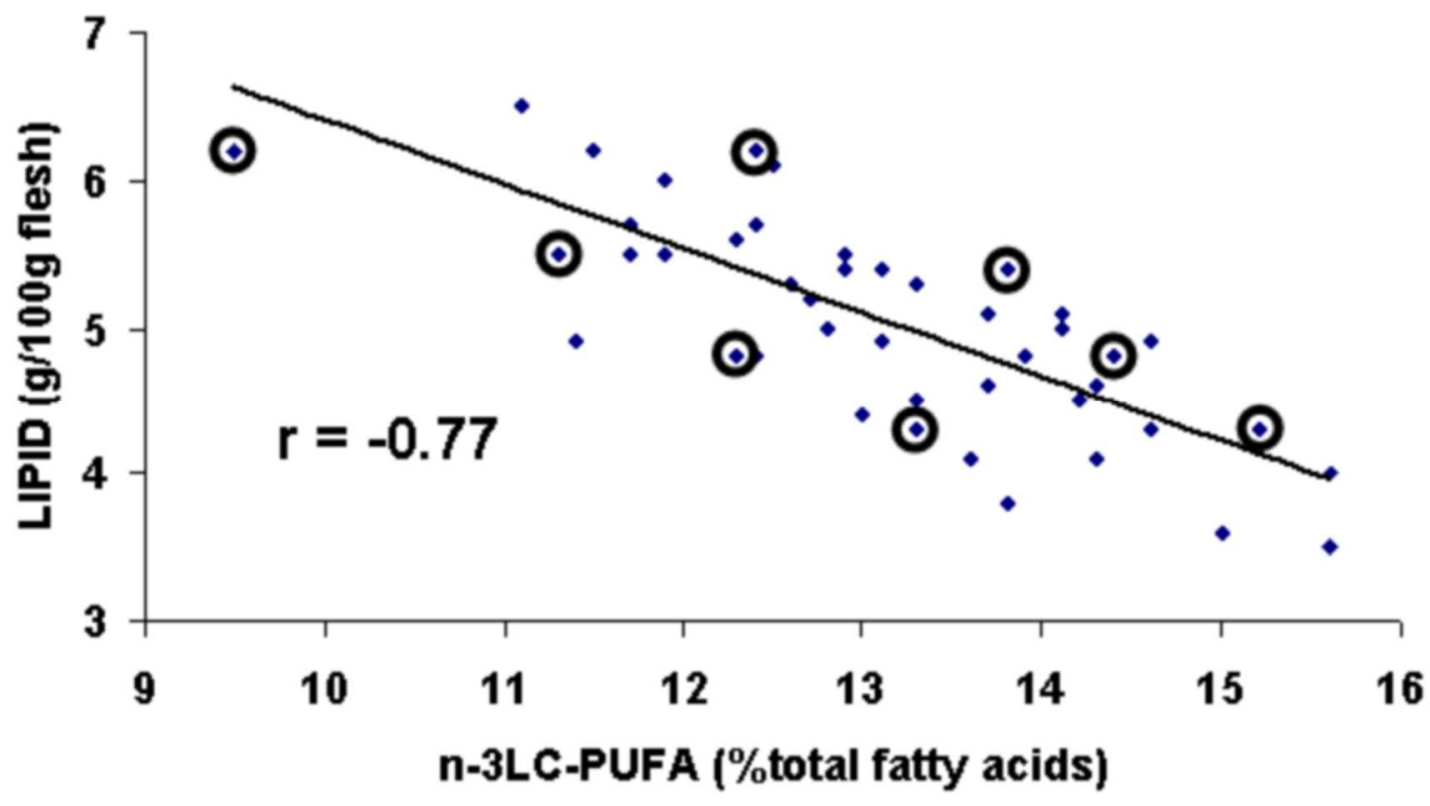

Figure 1. Correlation (Pearson) of family flesh percentage n-3LC-PUFA with family total lipid level. Ringed points indicate the data points for families used for microarray analysis. 
Tables

Table 1. Fatty acid content of diet

\begin{tabular}{cc} 
Fatty Acid & Percentage \\
\hline $14: 0$ & 1.2 \\
$16: 0$ & 17.4 \\
$18: 0$ & 2.9 \\
Total saturated & 22.9 \\
& \\
$16: 1 n-7$ & 1.1 \\
$18: 1 n-9$ & 36.8 \\
$18: 1 n-7$ & 2.0 \\
$20: 1 n-9$ & 3.3 \\
$22: 1$ & 1.1 \\
Total monoenes & 44.7 \\
& \\
$18: 2 n-6$ & 16.4 \\
$20: 4 n-6$ & 0.2 \\
Total n-6 PUFA & 17.2 \\
$18: 3 n-3$ & \\
$20: 5 n-3$ & 9.6 \\
$22: 6 n-3$ & 1.9 \\
Total $n-3$ PUFA & 2.3 \\
& 14.6 \\
Total PUFA & 32.4
\end{tabular}


Table 2. Lipid and growth parameters of families used for microarray analysis.

Percentage n-3LC-PUFA was calculated by adding percentages of 22:6n-3, 22:5n-3, 20:5n-3 and 20:4n-3 each expressed as a percentage of total fatty acids.

\begin{tabular}{cccc}
$\begin{array}{c}\text { Family } \\
\text { (Pairs) }\end{array}$ & $\begin{array}{c}\text { Lipid } \\
\text { (g/100g flesh) }\end{array}$ & $\begin{array}{c}\text { Percentage } \\
\text { n-3LC-PUFA }\end{array}$ & $\begin{array}{c}\text { Absolute } \\
\text { n-3LC-PUFA } \\
\text { (mg/100g flesh) }\end{array}$ \\
\hline 44 & $4.3 \pm 0.3$ & $13.3 \pm 0.8^{*}($ low $)$ & $481 \pm 16^{*}$ \\
43 & $4.3 \pm 0.1$ & $15.2 \pm 1.1$ (high) & $560 \pm 38$ \\
33 & $4.8 \pm 0.7$ & $12.3 \pm 1.3^{*}$ (low) & $504 \pm 52^{*}$ \\
36 & $4.8 \pm 0.3$ & $14.4 \pm 1.0$ (high) & $611 \pm 64$ \\
48 & $5.5 \pm 1.2$ & $11.3 \pm 0.9 *$ (low) & $557 \pm 121$ \\
10 & $5.4 \pm 0.6$ & $13.8 \pm 0.9$ (high) & $659 \pm 75$ \\
37 & $6.2 \pm 0.7$ & $9.5 \pm 0.8 *$ (low) & $512 \pm 106$ \\
6 & $6.2 \pm 0.8$ & $12.4 \pm 0.7$ (high) & $639 \pm 57$
\end{tabular}

* Difference for family pairs ( $p<0.05, t$-test) 
Table 3. Pairwise correlations coefficients (Pearson) between lipid and growth parameters in 48 salmon families.

\begin{tabular}{lcccc} 
& LIPID (g/100g) & $\begin{array}{c}\text { PERCENTAGE } \\
\text { n-3LC-PUFA }\end{array}$ & $\begin{array}{c}\text { ABSOLUTE } \\
\mathrm{n}-3 \text { LC-PUFA } \\
(\mathrm{mg} / 100 \mathrm{~g})\end{array}$ & INITIAL MASS \\
\hline PERCENTAGE n-3LC-PUFA & $-0.77^{*}$ & & & \\
ABSOLUTE n-3LC-PUFA & $0.68^{*}$ & -0.13 & & \\
INITIAL MASS & $0.338^{*}$ & -0.08 & $0.43^{*}$ & \\
FINAL MASS & $0.53^{*}$ & $-0.43^{*}$ & $0.40^{*}$ & 0.20
\end{tabular}

* significant correlation at $\mathrm{p}<0.05$ (t-distribution) 
Table 4. Heritability of flesh lipid parameters.

\begin{tabular}{lccc} 
& $\begin{array}{c}\text { Lipid } \\
\text { (g/100g flesh) }\end{array}$ & $\begin{array}{c}\text { Percentage } \\
\text { n-3LC-PUFA }\end{array}$ & $\begin{array}{c}\text { Absolute } \\
\text { n-3LC-PUFA } \\
\text { (mg/100g flesh) }\end{array}$ \\
\hline Heritability & 0.69 & 0.77 & 0.34 \\
Standard error & 0.14 & 0.14 & 0.11
\end{tabular}


Table 5. List of mRNAs from microarray analysis which are expressed at higher or lower level in salmon with high flesh n-3LC-PUFA compared to low.

Only those features which are significantly ( $p<0.05, T$-test), and greater than 1.25 fold higher or lower are listed. Shaded features are significant after false discovery rate correction.

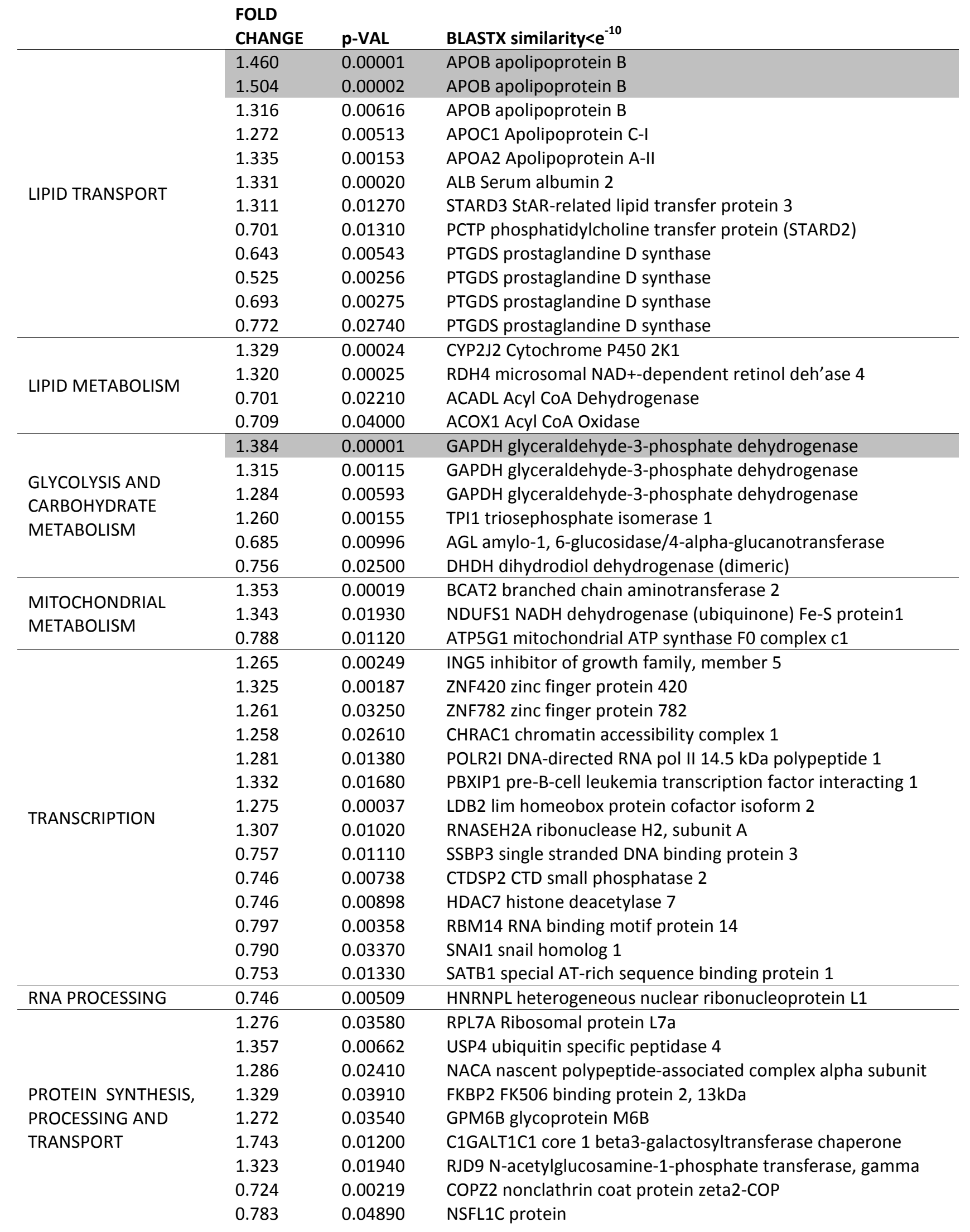




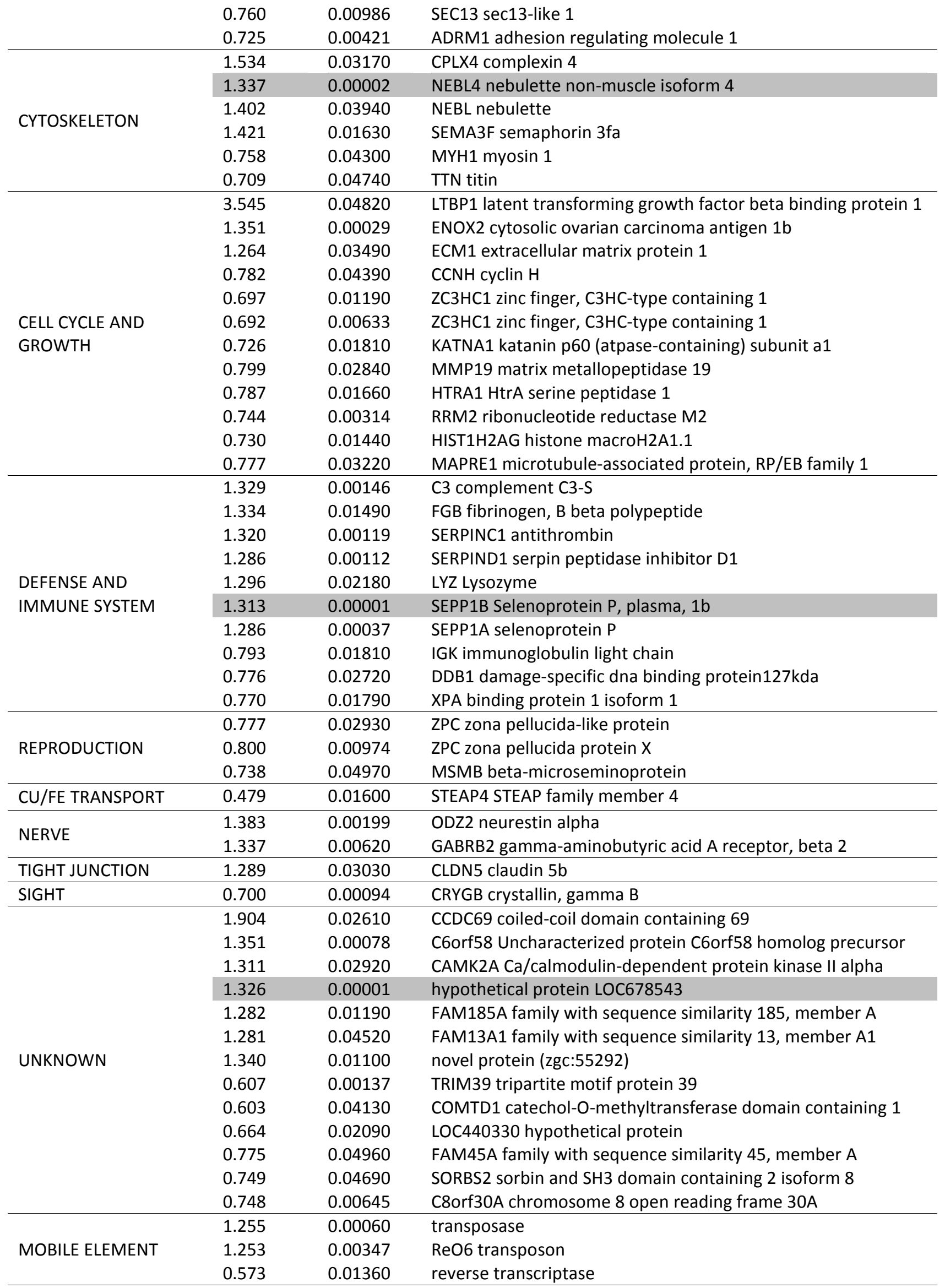


Table 6. Overrepresented Gene ontology (GO) biological process categories in salmon with high flesh n-3LC-PUFA compared to low.

\begin{tabular}{cccc} 
Category & $\begin{array}{c}\text { Genes in } \\
\text { Background }\end{array}$ & $\begin{array}{c}\text { Genes in } \\
\text { List }\end{array}$ & p-Value \\
\hline GO:51234: establishment of localization & 465 & 13 & 0.00119 \\
GO:6810: transport & 423 & 12 & 0.00178 \\
GO:6869: lipid transport & 13 & 2 & 0.0095 \\
GO:6820: anion transport & 26 & 2 & 0.036 \\
GO:15698: inorganic anion transport & 25 & 2 & 0.0335 \\
GO:278: mitotic cell cycle & 28 & 2 & 0.0413 \\
GO:51325: interphase & 11 & 2 & 0.0068 \\
GO:226: microtubule cytoskeleton organization & 17 & 2 & 0.0161 \\
GO:48731: system development & 52 & 3 & 0.0216 \\
GO:45045: secretory pathway & 31 & 2 & 0.0497 \\
\hline
\end{tabular}

'In Background', the number of genes present in the indicated GO category present on the total microarray. 'In List', the number of genes in the indicated GO category present in the output list (high \% $n$-3LC-PUFA versus low \% $n$-3LC-PUFA). The $p$-Value indicates the probability that the GO category is over-represented in the output list compared to the background list. 